\section{CLOSING THE CHANNEL OF OPPORTUNITY}

\section{Uncertainty surrounding Britain's future in EU research could be as damaging to science as the prospect of funding cuts onceit leaves the union.}

BY MARK PEPLOW

$\mathrm{H}$ elga Nowotny joined a vociferous chorus when she denounced the United Kingdom's momentous decision to leave the European Union, "It's a real loss for everyone - for the UK, and for European science," says the former president of the European Research Council (ERC).

Five months after the Brexit referendum and the country is still unsure exactly what it has voted for. The terms of the UK's departure are far from set in stone, but it is already clear that the outcome of that process will have huge significance for science, both in the UK and across Europe.

A wide range of factors underlies the strength of UK-EU partnerships. But for many researchers, they boil down to money, free movement, and broad collaboration: all of which would be weakened if the UK isolates itself from the EU funding schemes, agencies and rules that have fostered these partnerships.

"Without a big, bold plan to guarantee UK science's attractiveness, leadership and support of foreign researchers, the UK will haemorrhage talent and collaborations," claims Mike Galsworthy, the programme director of Scientists for EU, a group that campaigned for the UK to remain part of the EU.

UK universities receive about $16 \%$ of their research funding from the EU. Much comes directly from the vast $€ 75$ billion Horizon 2020 programme, which aims to foster multinational collaborations aimed at tackling big scientific questions and boosting innovation. About $€ 13$ billion of that pot is funnelled through large ERC grants, awarded for the highest-rated research. UK researchers have been particularly successful in winning these funds: from 2007 to 2013, they won $€ 1.67$ billion in ERC grants, some $22.4 \%$ of the total available and more than any other country.

\section{SHOW ME THE MONEY}

Immediately after the referendum, research collaborations across the EU were thrown into doubt. Fearing that UK researchers would no longer be eligible for these funding streams, some EU partners started to get nervous about having them on board. Scientists for EU has logged 40 examples where Horizon 2020 projects have been disrupted, for example because UK researchers have stepped down from coordination roles.

"I initially received condolences," says Aldo Sorniotti of the University of Surrey, who is involved in several EU consortia developing control systems for electric vehicles. His collaborators said that they were reluctant to invite him to join future consortia, and that it was no longer appropriate for him to lead any of the consortia. As his group receives most of its funding from the EU, this was a serious blow.

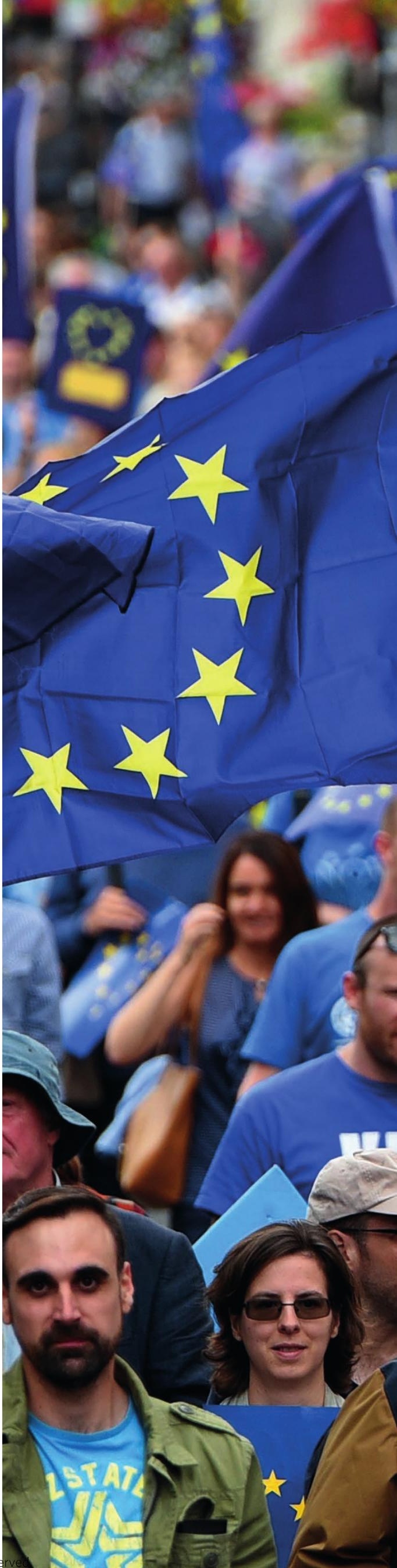


Thousands of people took to the streets for a series of protests against the referendum vote for Britain to leave the European Union. Many researchers fear for the future of collaborations with scientsts on the continent.

It soon became clear, however, that UK researchers would not immediately be denied EU funding. The European Commission encouraged UK researchers to keep participating in Horizon 2020, warned collaborations not to drop their UK partners, and emphasized that there would be no discrimination against UK researchers in funding decisions. "For the time being, nothing changes," says Lucía Caudet, spokesperson for research, science and innovation at the commission. The commission is also monitoring grant awards, and has not seen any anomalies suggesting that UK researchers are suffering. "After the initial shock, the situation is getting back to normality," says Sorniotti.

Some concerns may be assuaged by a UK government commitment in August that it will 'underwrite' any Horizon 2020 research funds applied for successfully before the country leaves the EU, offering a guarantee that British researchers will not lose that money.

But the government has not pledged to replace lost funding once the UK has left the EU. "It doesn't reassure me that we'll have access to EU funding after Brexit," says Paul Crowther, head of the physics and astronomy department at the University of Sheffield. "In the long term, after 2020, it will be very difficult to replace the funding I get from the European Commission," agrees Sorniotti. 
Paul Crowther, head of the physics and astromony department at Sheffield University, from which researchers have already been cut from an EU scheme because of uncertainty about their future funding eligibility.

\section{"WE WERE IN A VERY PRIVILEGED POSITION BEFORE, AND PEOPLE ARE JUST WAKING UP} TO THAT,"

Whether or not UK researchers will have access to those funds after the UK leaves is one of the many unknowns that must be resolved in the coming negotiations. And any loss of EU funds could expose a weakness in the UK's domestic science support, says Crowther: "UK funding has eroded against inflation over the past decade, and it's the flagship EU grants that have helped to mitigate against that."

In May, Digital Science (a London-based consultancy, whose owner also has a stake in Nature's publisher) estimated that Brexit could create a $£ 1$ billion funding gap for UK researchers. The UK's leading universities could be amongst the hardest hit. Nature Index data show that the universities of Cambridge and Oxford, for example, were the UK's most enthusiastic collaborators with other EU countries; making up 48 of the 100 most productive partnerships between two institutions (one from the UK, one from the EU) publishing papers together in top journals. According to Digital Science, Cambridge receives $20 \%$ of its academic research funding from the EU, and Oxford 23\%.

\section{DREAM TEAM}

Money is only part of the story. The UK has benefitted enormously from its ability to attract top talent from other EU countries, according to Nowotny. "If you lose that, you'd be nowhere," she says.

The ability to work anywhere within the EU has also made it easy for project collaborators to spend time in the UK, or vice versa. "Freedom of movement has proven extraordinarily fruitful for science," says one post-doctoral researcher in theoretical physics, who spoke to Nature Index on condition of anonymity.
Brexit may limit that mobility in the future. "I'm at the stage in my career where that uncertainty is extremely damaging," the postdoc says. Shortly before the referendum, he had been offered jobs in the UK and in North America. "I was on a knife's edge," he says. "But when the referendum result came out and it became clear to me that science would suffer, it was the straw that broke the camel's back". He started his new job across the Atlantic in September.

Crowther is concerned that the UK will lose access to one of the funding mechanisms that has boosted mobility, known as the Marie Skłodowska-Curie actions. The programme provides grants for early-career researchers to spend a year in collaborators' labs, or to support meetings of large groups. "They're very good for training researchers, and giving them exposure to different groups and expertise," he says. Yet researchers in his department have already been cut from one of these schemes because there was concern that "if the walls went up", students would not easily be able to travel to the UK. "The uncertainty is already affecting UK participation in these projects," he says. "It's a shame." The European Commission declined to comment on this specific case.

Large multinational collaborations involving the UK and other EU members have also led to significant advances in some fields, says Galsworthy, because they have allowed EU researchers to tackle complex multidisciplinary questions, sharing resources, ideas and expertise that a single country could never tackle on its own. "You can put together a dream team," he says.

For example, the EU has overseen a series of ground-breaking projects to understand the health impact of low doses of radiation, and put $€ 1$ billion into the Graphene Flagship, a 10 -year programme to develop applications for atom-thin materials. Common EU rules on data standards, clinical trials and animal testing help to enable these sorts of projects, he adds.

Indeed, the UK's strength in science has made it a popular partner for collaborations, creating a virtuous feedback loop that has helped to boost the UK's share of grants from the EU science budget. This in turn gave the UK a big say in setting the agenda for the EU's massive science programme. Now, it is set to lose that influence. Discussions on the successor to Horizon 2020 will begin next year, and the UK will probably not be part of those, says Nowotny.

But the European Commission says that depends on whether the UK has formally declared its intention to leave the EU, by invoking article 50 of the Lisbon Treaty. Until that happens, the country will participate as a full member of the EU. Above all, it is this kind of uncertainty over the UK's future relationship with the EU that is likely to stifle research in the coming years. "We are going to be in limbo for some time," says Crowther.

Some researchers hope that the UK could eventually strike a deal that allows it to pay a contribution in return for its researchers having access to programmes like Horizon 2020. Norway, not a member of the EU, has this kind of arrangement, but it must also accept freedom of movement for EU citizens to the country, something that committed Brexit supporters in the UK are dead-set against. "We're in for a few years of mess," says Galsworthy. "We were in a very privileged position before, and people are just waking up to that". 


\section{BRITISH AND EUROPEAN RELATIONS}

An analysis by Nature Index shows that more than 700 UK institutions collaborated with EU institutions to publish papers in the high-quality journals in the index in 2015 (graph 1; institutional collaborations by subject graph 5). The average collaboration score between the UK and other partners (graph 2) is a measure of the partnership's strength and considers each partners' contribution to collaborative papers in the index. For UK-EU collaborations, that score topped 150 in 2015, and was on a rising trend; in contrast, the score for UK collaborations with the rest of the world had remained between $\mathbf{4 0}$ and $\mathbf{5 0}$ since 2012. Partnerships are the total number of bilateral collaborations between a UK institution and a counterpart in the EU, or outside the EU (graph 3); also shown by subject (graph 4 ).

\section{UK institutions involved in} global partnerships

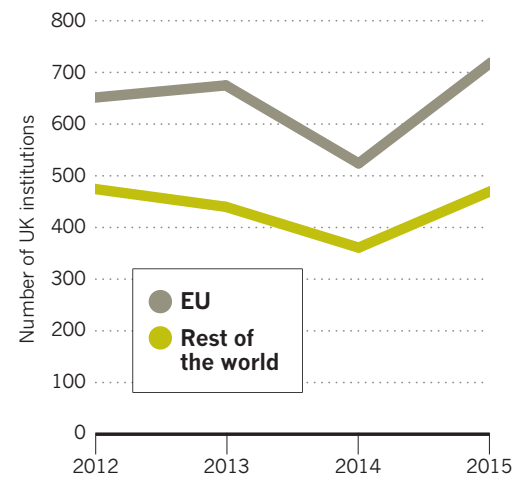

\section{Average collaboration score of UK} institutional partnerships, global

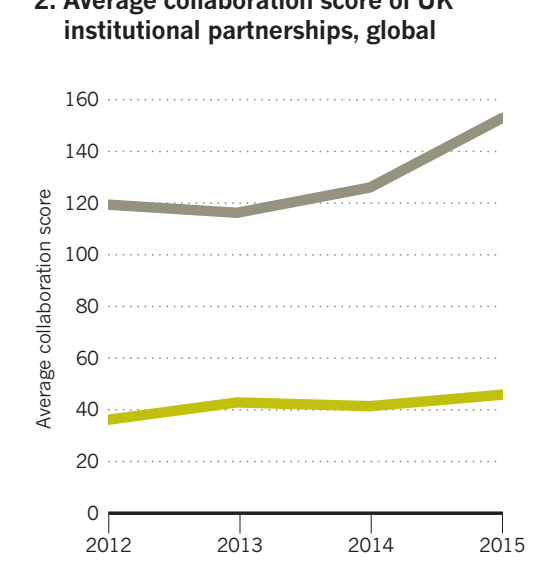

5. UK institutions collaborating with EU, by subject

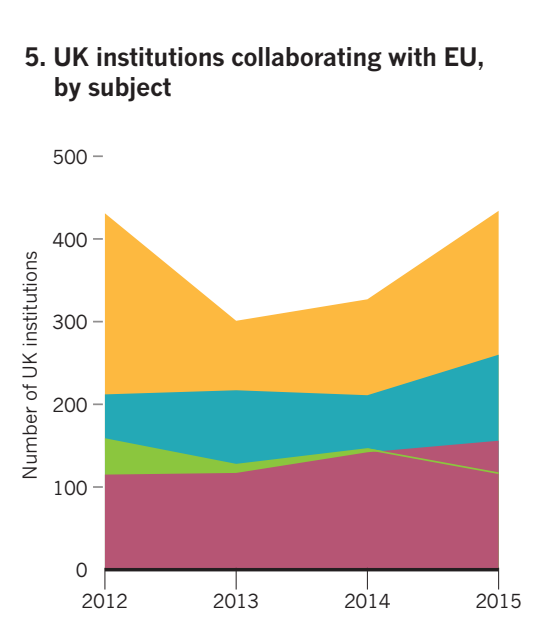

3. UK institutional partnerships, global

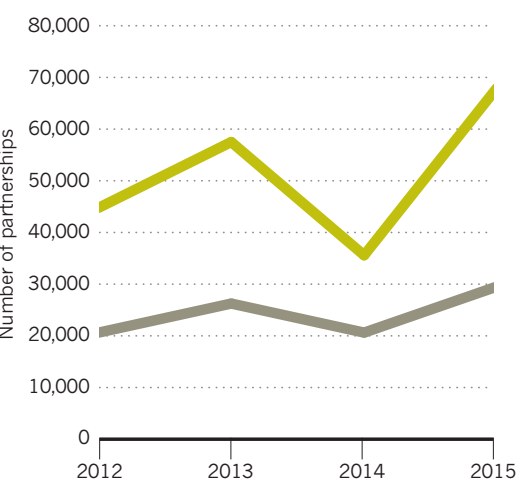

4. UK-EU institutional partnerships, by subject
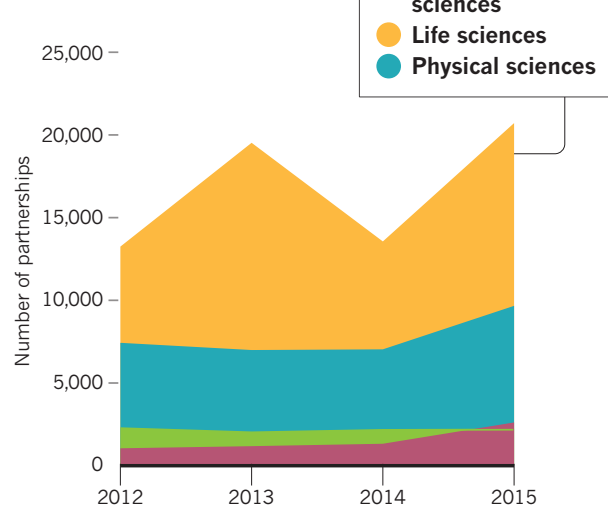

Chemistry

Earth and environmental sciences

Life science (1)

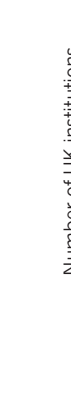

\section{UK's top 5 EU partnerships overall}

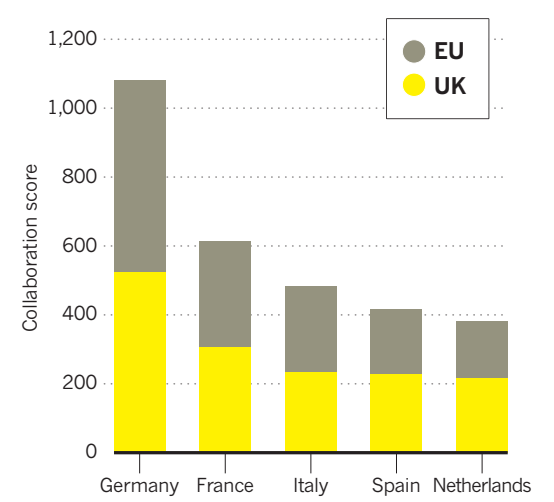

Top 10 UK-EU collaborations

The collaboration score (CS) between two partnering institutions is the sum of the fractional count (FC) for collaborative papers with authors from both institutions.

\begin{tabular}{|c|c|c|c|c|}
\hline UK & EU & $\begin{array}{l}\text { TOTAL } \\
\text { CS }\end{array}$ & $\begin{array}{l}\text { UK } \\
\text { CONTRIBUTION }\end{array}$ & $\begin{array}{l}\text { EU } \\
\text { CONTRIBUTION }\end{array}$ \\
\hline University of Cambridge & National Institute for Astrophysics, Italy & 35.11 & 12.14 & 22.97 \\
\hline University of Oxford & Pierre and Marie Curie University - Paris 6, France & 21.6 & 14.84 & 6.75 \\
\hline University of Cambridge & Pierre and Marie Curie University - Paris 6, France & 19.2 & 13.48 & 5.73 \\
\hline Liverpool John Moores University & National Institute for Astrophysics, Italy & 17.97 & 5.07 & 12.9 \\
\hline Durham University & Leiden University, Netherlands & 17.6 & 11.19 & 6.41 \\
\hline University of Oxford & Paris Institute of Astrophysics, France & 16.88 & 7.41 & 9.48 \\
\hline University of Cambridge & Heidelberg University, Germany & 16.79 & 8.17 & 8.61 \\
\hline University of Cambridge & European Southern Observatory, Germany & 14.77 & 8.16 & 6.61 \\
\hline University of Oxford & University of Copenhagen, Denmark & 14.44 & 7.77 & 6.67 \\
\hline University College London & National Institute for Astrophysics, Italy & 14.43 & 6.23 & 8.21 \\
\hline
\end{tabular}

